\title{
Balancing the educational choices in the decision-making of a dean of medicine: Fission or fusion?
}

\author{
J E Wolvaardt, ${ }^{1}$ BCur, MPH, PGCHE, PhD; B G Lindeque, ${ }^{2}$ MB ChB, MMed, MD, GKOG; P H du Toit, ${ }^{3}$ BA, HED, BA Hons, MEd, DTI, PhD
}

${ }^{1}$ School of Health Systems and Public Health, Faculty of Health Sciences, University of Pretoria, South Africa

${ }^{2}$ School of Medicine, Faculty of Health Sciences, University of Pretoria, South Africa

${ }^{3}$ Department of Humanities Education, Faculty of Education, University of Pretoria, South Africa

Corresponding author: J E Wolvaardt (liz.wolvaardt@up.ac.za)

Background. The literature on deans of medicine focuses mostly on the qualifications, roles, abilities, management and leadership competence of the deans. The gap between theory and practice is, however, the nucleus of the position.

Objectives. To describe insights into the educational forces that act on a dean of medicine and the implications for those who wish to bring about change - in this case, changes in the inclusion of public health in the medical curriculum.

Methods. A series of in-depth interviews of a vice dean (VD) of medicine was conducted over a period of a year. The interviews were transcribed. Initial in-depth analysis of the transcriptions was done using open coding, prior to a second round of coding that resulted in themes.

Results. The interviews revealed a serendipitous aspect, namely the ontological realities of the VD's practice. This practice is characterised by balancing multiple internal and external forces, such as the breadth and depth of the curriculum that acts on the medical curriculum.

Conclusion. The ontological realities of the VD bring to life the qualifications and leadership, and management competence, roles and abilities described in the literature. The multiple - often opposing - educational choices that deans face are an inescapable reality of deanship. Medical deans must balance these opposing forces to ensure fusion within the curriculum, and those interested in changes, such as strengthening the teaching of public health in this curriculum, need to plan on how to overcome this.

Afr J Health Professions Educ 2016;8(1):25-29. DOI:10.7196/AJHPE.2016.v8i1.474

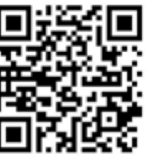

If one can compare deanship to an atom, then the focus in the literature is on the physical manifestations of deanship as a source of support, funding and problem solving rather than the nucleus. ${ }^{[1-3]}$

This article outlines some insights into deanship that emerged as a result of the first author's exploration of teaching public health in the medical curriculum. In exploring the inclusion of public health, the serendipitous understanding of what it entails to hold a medical curriculum together for a vice dean (VD) of medicine in a South African (SA) university surfaced. At this particular university, the chairperson of the school of medicine (similar to dentistry) also holds the position of the VD of medicine. The two remaining schools, healthcare sciences and public health, do not have VDs. It is the second of these two schools that, although a postgraduate school, is responsible for the inclusion of public health in the undergraduate medical curriculum.

One consequence of this separation between a school of public health and a school of medicine is that although the responsibility for the inclusion of public health rests with one school, the students and the curriculum in which public health is included are those of another school.

The series of interviews with the VD were conducted with the primary intention of better understanding the original curricular intentions, curricular development and current inclusion of the public health curriculum in the medical curriculum. Among the journal articles that focus on deans of medicine, the emphasis is on the qualifications, competence, abilities and personal qualities.

\section{Qualifications and experience}

Deans of medicine are usually described as being medical specialists with a reputation in clinical expertise and research in their field of expertise.
Deans usually come from mainstream specialties such as internal medicine, surgery, and obstetrics and gynaecology, and are often appointed in their fifties. ${ }^{[2]}$ The professional pathway followed by the dean is immaterial (academic, clinical or administrative) ${ }^{[2]}$ However, the most common criteria used in the selection of deans (excellence in clinical practice and research) are insufficient in themselves to fulfil the leadership role.

\section{Leadership and management competencies}

Various understandings exist on what constitutes leadership and management practice. The purpose in this article is not to engage in the debate on leadership and management, but rather to highlight how both are considered desirable attributes. The management and leadership competencies described by Rich et al. ${ }^{[4]}$ are based on a comprehensive review of 33 sources, but it is the need to create a common vision that is of particular interest. ${ }^{[1,2,4]}$

Medicine focuses on decision-making at the individual physician-patient level. Leadership necessarily involves stepping away from this relationship and examining problems at a systems level, requiring the ability to view issues broadly and systemically. ${ }^{[5]}$ At the nucleus of systems thinking is the ability 'to balance the interests of several conflicting interests with an ultimate focus on the benefit of the institution as a whole. ${ }^{[2]}$ Also popular in the literature are the desirable skills and abilities required.

\section{Skills and abilities}

The differences between skills or abilities are, again, better debated elsewhere, but what is clear is that a wide range of both is required.

The literature suggests that the skills required to create common goals of communal achievement include patience, persuasion, communication and 
interpersonal skills. ${ }^{[2,6]}$ Patience is required not only in the act of persuading others, but as a more generic ability to tolerate ambiguity - an inescapable reality of management, but not necessarily of doctors in the diagnostic process. ${ }^{[2]}$ Despite working within a management environment that has few diagnostic tests, the dean is nevertheless expected to 'act decisively, and achieve an appropriate balance between flexibility and assertiveness. ${ }^{[2]}$

Interpersonal skills identified include diplomacy, and communication skills including listening skills, facilitation and spiritual sensitivity. ${ }^{[2]}$ Among the professional and technical management skills, fiscal expertise, planning, problem-solving, organising, and administering are just a few. ${ }^{[2]}$

These skills and abilities of the envisaged successful dean overlap with the personal qualities that are needed to fulfil the role(s).

\section{Roles and personal qualities}

Among the plethora of roles, the primary roles of the dean are to ensure that the medical school flourishes and to foster a deeper understanding of why it is important to flourish. ${ }^{[2]}$ Successful deans are described as having high professional competence combined with human relation skills and the ability to administer a complex programme, and personal qualities, such as openness and objectivity. ${ }^{[2,6]}$ The personal qualities of honesty and integrity, and the ability to address conflict of interest so that decisions are fair, consistent and transparent, are valued, as well as 'tenacity, stamina, longterm wisdom, emotional intelligence ... equanimity. ${ }^{\text {' }}$

It is surprising that we have any who meet these criteria listed in the literature. The aim of this article is to highlight the often opposing educational choices an experienced dean of medicine faces - a key consideration for those who wish to bring about change in the curriculum.

\section{Methods}

A constructive grounded approach using qualitative methods, as described by Charmaz, ${ }^{[7]}$ was used. The longitudinal series of interviews formed part of the first author's action research design, ${ }^{[8]}$ aimed at her professional development.

\section{Ethical considerations}

Ethical approval for the overarching study of exploring the inclusion of public health in the medical curriculum was granted by the University of Pretoria's Faculty of Education ethics committee (HS10/05/01). Written informed consent for the interviews was obtained from the VD.

\section{Data gathering}

Qualitative data were obtained through a series of three semistructured in-depth interviews over the period of a year. Each interview with the VD started with a trigger question:

- Interview one: What is the next big idea in medical education? (Academic Medicine Question of the Year, 2011)

- Interview two: The Health Professions Council of South Africa (HPCSA) regulations refer to having medical public health as a prominent curriculum theme. So what do you think they envisage/want with this inclusion?

- Interview three: So what roles (for our medical students) do we consider ideal?

The interviews were exploratory and dialectic in nature and were videotaped for transcription by an expert. The transcription was checked by the first author as the interviewer, and member-checked by the VD. An initial in-depth analysis of the transcriptions was done using open coding, and a constant comparative method suggested by $\mathrm{Tesch}^{[9]}$ was used to form and delineate categories, and to discover patterns in the data. The second round of coding included axial coding that resulted in themes. A software package for qualitative data (NVivo 8) was used for data management. Agreement of the themes was reached through discussion between the authors.

\section{Crystallisation}

In this research, crystallisation replaced triangulation, as triangulation implies that the outcome is a fixed position. In contrast, crystallisation allows a 'more complex and deeper understanding of the phenomenon. ${ }^{\text {'10] }}$ Crystallisation was ensured by inviting other specialists in deanship in health sciences to peer review this article. These experts were a current dean of medicine from another African university, a VD of research and a director of a school of medicine from two other SA universities, and a senior experienced academic from another institution who had never been a dean or VD. The participants were asked to critically read the article and to reflect whether the account is an authentic reflection of their own reality, and also to identify any additional educational forces that influence their decision-making in education.

\section{Results}

The core theme that emerged from the text is that of constant pressure of often-conflicting interests. This main theme is supported by six subthemes:

- Balancing those who use blocking strokes and those who hit for the boundary in education

- Balancing the breadth and depth of the curriculum

- Balancing the interests of the many and the interests of the few

- Balancing the individual focus and population focus

- Balancing teaching in the academic complexes and in the field

- Balancing international and local realities.

To represent the complexity of medical education, extensive use is made of verbatim text as the authentic voice of the $\mathrm{VD} .^{[11]}$

\section{Balancing those who use blocking strokes and those who hit for the boundary in education}

The profiles of academic staff include those who model their teaching practice on their own experience as undergraduate students so that 'we still have some people who read from a textbook. These members of the academic team are 'just ... blocking like we were taught before ...' using predictable serviceable classroom techniques of lecturing. But the milieu has changed and as a result there are those who have been included in the team who are engaged in their educational practice as well as their clinical practice, and who are using educational strategies that, in effect, have changed the game:

'In the modern game of cricket everything has changed. Because I think you are right. I think that some of the people who are out there batting, who are teaching the students, who were taught in a conventional sense and their game ... is no longer adequate for the challenges at hand. We have to devise new strokes ....

But the challenge of combining traditional and modern styles of teaching fades in the face of the major challenge of deciding the breadth and depth of the curriculum. 


\section{Balancing the breadth and depth of the curriculum}

Each school of medicine has to decide on what must be included in the curriculum, and how much time each inclusion will have.

'Historically, when I was a medical student, um, the curriculum was driven by what the lecturers thought the students should know. So it was totally a lecturercentred thing, giving us a story and, in fact, they dictated so we had to write down. So that has soon been replaced then by a sort of a student-centred thing where we ... identify themes and the students must solve problems.'

Although the curriculum is no longer characterised by what the academic staff consider important on the day, there is still a balance to be struck between the breadth and the depth.

'In the US you have all these [clinical] offices next to one another ... but here we have hundreds of kilometres between people, so that is quite difficult. So wide, wide knowledge, but not necessarily deep, means that they [the students] must be able to recognise and not necessarily be able to deal with everything ... We use what we call the Nijmegen criteria.'

The Nijmegen criteria that provide a typology for the levels of knowledge and skills required by a student are useful to curtail dominance of any particular academic staff member's personal research or clinical interest within the curriculum.

'Our motto says, a wide but not necessarily deep ... and the depth varies with the different conditions. It's a bit like the seabed. Wide, however, is essential because they are out there in the field. So that is why we expose them to 18 blocks, 13 special activities and 12 exit rotations as a final-year student and that defines the width.'

But this decision also comes at a price:

'... that means that we spread the marmite very thin on the bread.'

The decision to focus on 'messages of the reality and not necessarily the messages of complete academic theory' is not necessarily met with universal approval, in that 'in most people's hearts there is a desire to cover everything.' Clearly, these curricular decisions have to be reinforced to work against the desire to have saturation of theory as 'the not ... not covering everything is also a new thing that we have to work on' and this constant balancing results in a changing stability 'so there is evolution all the time'.

But it is not the constant struggle for balance between breadth and depth of the curriculum alone that is the cause of the VD's insomnia:

'My difficulty does not come with the departments or the blocks that have

a standardised programme. My difficulty is those who still make use of whatever patient is in the ward.'

The pull of the past curriculum can still be felt in the present curriculum:

'My personal favourite is that while in this curriculum, we still have one lecture for prostate cancer, which is the leading cancer of men and one lecture of cervix cancer, which is the leading cancer of women and while we have one lecture for heart attack ... we spend a week on the Krebs cycle, which nobody has actually seen.'

The push and pull continues also with placing blocks within the curriculum, with slots within the senior years more desirable than the early years:

'Not everybody can have the students for the last block ... everybody would like that.'
A primary intention of the medical curriculum is that the learning experience will prepare students for professional practice, and while not all can be achieved within the curriculum alone, the curriculum needs to anticipate a future reality. Balancing the known with the unknown:

'... so, the preparing for the hardness of a community service, we expose them to that but in a controlled way and we hope that the concept of width with a varying degree of depth with increasing competencies in the intern year, will allow them to be properly armed for the whole thing.

Balancing the interests of the many and the interests of the few The global consensus on social accountability considers the priority health concerns of the community as the departure point for education, research and service delivery. ${ }^{[12]}$ However, the priority needs of the community (or the many) are not necessarily in line with the scientific interests of the academic staff members (or the few). Even within the lecture halls, this tension between what students need to know (the common) v. what is cutting-edge science, is played out:

'Listen, the wheel keeps on turning and ... now we know a lot of things. We know about the human genome. We know about multidrug-resistant [tuberculosis] TB. We know about all those things but your training should reflect what's happening in your community'

This strain is not felt by academic staff alone:

'And the student on the other side sits there and I think everything weighs kind of equally. Gynaecology - we see one new patient with cervix cancer every day and most days more than one new patient with cervix cancer, which is, which is ... a lot. And we see about one patient with cancer of the fallopian tube every third of a year. So we might see three a year. Yet the students will take the two chapters in the book as equivalent.'

The central anchoring point is to ensure a 'new commitment for a gain for relevance [to undergraduates]' and part of this striving for relevance is the inclusion of public health in the curriculum.

\section{Balancing the individual focus and population focus}

The debate surrounding the inclusion of a population focus, such as public health, in the curriculum that focuses on individuals, is well summarised. ${ }^{[13]}$ The decision of the HPCSA to include public health in the medical curriculum renders the decision moot. What remains, however, is not 'should we' but questions of 'how', 'when' and 'why'?

It was this inclusion that was of primary interest for the interviews and it became clear that there has been some evolution in the curriculum:

'But that is basic sort of old-style public health, where you get health inspectors and that sort of stuff ... we have moved on.'

The status of the health of the public now serves to inform the medical curriculum:

'We have an epidemic of trauma and, uh, violence ... that can only be known if you look at what is happening in the community and from there on, the competencies should be designed to deal with crises and so on, uh, with lesser events. Which doesn't mean that we shouldn't tell them about Addison's disease or something that happens rarely?'

This role of public health, not only to inform, but also to interpret, is elaborated on: 
'... public health medicine must tell us what is happening, what it's prioritising and what is the context and hopefully that will lead to a complete understanding of where we are.'

Among the myriad decisions that surround the inclusion of public health, none are so central than whether to embed public health in mainstream medical teaching or encapsulate public health in one or more stand-alone modules/blocks/activities. The inclusion to embed public health relies on the academic staff from the school of medicine feeling able to include a population perspective.

'So if we talk about cervix cancer, I'm supposed to give a public perspective as well as not.'

One negative design effect of embedding public health is that it is then virtually impossible to evaluate the inclusion and this in turn is problematic in an environment that requires evidence of the inclusion for accreditation purposes:

'On the other hand, one of the things that we have to be comfortable with is whether ... it's ... this behind the scenes and visible work ... so to be rated on something that is behind the scenes will lead to a limited yield.'

Balancing teaching in the academic complexes and in the field In SA, filling clinical posts outside the metropolitan areas is notoriously difficult and finding those who are then also prepared to support students at these teaching sites is a constant headache:

'So at least there is one teacher per hospital where the students go who have actually said, "I am prepared to take part in this process as a teacher". Better than that in our social economic situation, and our staff situation, is pretty hard to get.'

Difficult or not, this imperative of widening the training platforms is unavoidable, and is driven by trends in medical education, rising student numbers and the need to reduce the dominance of hospital-centric training for students. This dispersed model of training brings about an additional tension, that of involving others:

'Ah, the hard thing is that we then delegate our in loco parentis responsibility to people who are very far from us, and who are not necessarily buying into the system of being a teacher.'

In many cases, the health professionals in question are not fellow medical colleagues:

'... so the sisters in the clinics don't see these visits that the kids come and do every two weeks and ... they say "Oh, here they are again and we already have 300 people waiting here." So that's a hard match at the moment.'

\section{An additional strain is that of content in the field:}

'Community-based teaching, where the students are predominantly trained in the community, depends on a principle that they will see what they need to see because they are there.'

But the ability to handle ambiguity is a key ability for a dean, not the average medical student. The counterweight argument of student support, through guided reflection of these community experiences, is then yet another factor to consider.
If support of the students in training is not problematic enough, then preparation of students to cope beyond the reach of support is almost unimaginable. Much of the clinical practice and experience required for final professional registration takes place in the community-service years. But reality is somewhat different from expectations in that

... they work then in the state sector which was supposed to be a comm[unity] serv[ice] year under supervision but that has been abandoned because there is no supervision. So they now work within the constraints of what they are presented with ... and that means that there is not necessarily an expected growth in procedural competencies.'

\section{Balancing international and local realities}

The commissioned Lancet article outlined what international authors consider the third reform period in medical education. ${ }^{[14]}$ What is important in the context of this article is not the content of that reform, but the acknowledgement that these sentinel theories expand our local thinking about medical education. One example is the question of whether to make use of interprofessional education:

'I'm not sure that that's the ideal myself because ... any programme that you enter, you have to have ... a prime knowledge. So, if the knowledge base of all the professions is the same, then it's pretty easy to go into a joint programme. If the knowledge bases are different or if the expectations or the objectives are different, you will have a staggered, non-equal outcome of a joint thing.'

Resisting the attraction of opting for the simple adoption of international educational strategies is the messy complexity of our local reality. We are:

'... still developing [as] an evolutionary system [where] patient numbers is a strength, it is not a problem. We all have our own problems, it is just ours seem less exotic so that it is a dangerous phenomenon to think that if you talk about great things that they see on the TV, then they think that this is the real thing, whereas the rest, the bread and buttery sort of stuff, might not be regarded as important.'

Feedback from the critical readers supports this authentic account of the experience of being a dean or VD of medicine, with one respondent who added two additional sources of tension: the demands of the Department of Health as the employer and the demands of the regulatory bodies.

\section{Summary}

This article outlines a complex picture of forces and counterforces on the medical curriculum in general, and the energy required by the VD to bind these forces into a stable whole. There are subthemes of balancing: those who use blocking strokes and those who hit for the boundary in education; the breadth and depth of the curriculum; the interests of the many and the interests of the few; the individual focus and population focus; teaching in the academic complexes and in the field; and international and local realities. These emphasise the required systems thinking ability of the VD, who needs to balance multiple conflicting interests to benefit the institution. ${ }^{[2]}$

The ontological reality of the VD in this research brings to life the qualifications, experience, leadership and management skills, and roles and abilities, described in the literature. While leadership and support of the dean are necessary for enhancing the teaching of public health, ${ }^{[15]}$ the complex forces of often-opposing educational choices is a significant factor to effect change. The literature suggests that within this reality of multiple 
educational choices, the development of a common educational vision is fundamental to effecting the required changes. ${ }^{[1,2,4]}$

\section{Conclusion}

This article is an in-depth description of the ontological reality of one VD of medicine at one medical school. Through crystallisation, it became apparent that this reality is a common one for those who occupy similar positions. The forces that exert pressure on the curriculum, such as international or local realities, are an inescapable aspect of practice. Similarly, deans of medicine have to strike a balance in teaching in the academic complexes and teaching in the field. The debate on the inclusion of a population focus in the individual focus of medicine should never end, and the interests of the many do not have to annihilate the interests of the few. Those who wish to bring about change in any medical curriculum - in this case strengthening the teaching of public health - need to be cognizant of the pressure of educational choices that act on the dean and need to be able to create a common educational vision to justify the changes.

Acknowledgements. The authors would like to acknowledge the contribution of the following critical readers for their valuable input: Prof. M. Chidzonga, College of Health Sciences, University of Zimbabwe; Prof. N. Ebrahim, Director of the School of Medicine, University of Limpopo (MEDUNSA), South Africa; and Prof. J. Frantz, Deputy Dean of Research, Faculty of Community and Health Sciences, University of the Western Cape, South Africa.

\section{References}

1. Bassaw B. Determinants of successful deanship. Med Teach 2010;32(12):1002-1006. [http://dx.doi.org/10.3109 /0142159X.2010.497821

2. Lee A, Hoyle E. Who would become a successful dean of faculty of medicine: Academic or clinician or administrator? Med Teach 2002;24(6);637-641. [http://dx.doi.org/10.1080/0142159021000063970]

3. Chapman J. Reflections on the medical deanship. Acad Med 1998;73(6):654-656. [http://dx.doi.org/10.1097/00001888 199806000-00011]

4. Rich E, Magrane D, Kirch DG. Qualities of the medical school dean: Insights from the literature. Acad Med 2008;83(5):483-487. [http://dx.doi.org/10.1097/ACM.0b013e31816becc9]

. Collins-Nakai R. Leadership in medicine. Mcgill J Med 2006;9(1):68-73.

6. Yedidia MJ. Challenges to effective medical school leadership: Perspectives of 22 current and former deans. Acad Med 1998;73(6):631-639. [http://dx.doi.org/10.1097/00001888-199806000-00007]

7. Charmaz K. Constructing grounded theory: A Practical Guide Through Qualitative Analysis. Thousand Oaks, California: Sage Publications, 2006:123-150.

8. Whitehead J, McNiff J. Action Research: Living Theory. London: Sage Publications, 2006.

9. Tesch R. Qualitative Research. Analysis Types and Software. London: Falmer Press, 1990.

10. Nieuwenhuis J. Qualitative research designs and data gathering techniques. In: Maree K, ed. First Steps in Research. Pretoria: Van Schaik Publishers, 2007:70-97.

11. Regehr G. It's NOT rocket science: Rethinking our metaphors for research in health professions education. Med Educ 2010;44(1):31-39. [http://dx.doi.org/10.1111/j.1365-2923.2009.03418.x]

12. Global Consensus for Social Accountability of Medical Schools, 2010. http://my.ibpinitiative.org/Community aspx?c=c5357538-ce2a-4627-94f6-6110addbe047 (accessed 22 April 2013).

3. Woodward A. Public health has no place in undergraduate medical education. J Public Health Med 2004;16(4):389-392.

14. Frenk J, Chen L, Bhutta Z, et al. Health professionals for a new century: Transforming education to strengthe health systems in an interdependent world. Lancet 2010;376(9756):1923-1958. [http://dx.doi.org/10.1016/S01406736(10)61854-5]

15. Johnson I, Donovan D, Parboosingh J. Steps to improve the teaching of public health to undergraduate medical students in Canada. Acad Med 2008;83(4):414-418. [http://dx.doi.org/10.1097/ACM.0b013e318166a8e4] 